The aim of this hypothesis is to provide new insights into the still unclear mechanisms governing airway inflammation in cystic fibrosis. Although the genetic basis of cystic fibrosis as well as the molecular structure of cystic fibrosis transmembrane regulator (CFTR), the mutated protein which causes the disease, have been well defined, a clear relationship between the genetic defect and the pulmonary pathophysiology, especially chronic infections and neutrophildominated airway inflammation has not been established. Cystic fibrosis is thus a unique pathological situation in that neutrophils can be depicted as both an antiinfectious and a proinflammatory cell. In cystic fibrosis there is an emerging picture of an imbalance between these two roles with both a reduction in the antiinfectious efficacy and an augmentation of the proinflammatory functions. Better knowledge of fundamental defects in neutrophil function in cystic fibrosis as well as a novel cellular function of CFTR, which will be reviewed, will allow identification of potentially new clinical targets and aid selective therapeutic action aimed at counteracting the lethal neutrophil-induced airway inflammation. The rationale for colchicine therapy is a significant example of a drug which might act both at the molecular levels on CFTR expression in epithelial cells and on neutrophils to mediate antiinflammatory effects. Preliminary results are presented in this issue (Med Inflamm 1999; 8: 13-15).

Key words: Cystic fibrosis; Inflammation; Cystic fibrosis transmembrane regulator; Neutrophils

\section{Inflammation and CFTR: might neutrophils be the key in cystic fibrosis?}

\author{
V. Witko-Sarsat, ${ }^{1}$ I. Sermet-Gaudelus, ${ }^{2}$ G. Lenoir ${ }^{2}$ \\ and $B$. Descamps-Latsch $a^{1, C A}$ \\ ${ }^{1}$ INSERM U507 and ${ }^{2}$ Service de Pédiatrie II, Hôpital \\ Necker Enfants-Malades, Paris, France \\ ${ }^{\mathrm{CA}}$ Corresponding Author \\ Tel: (+33) 0144495376 \\ Fax: (+33) 0145665133 \\ Email: b.descamps@necker.fr
}

\section{Genetic basis and pathogenesis of cystic fibrosis}

Cystic fibrosis (CF) is a chronic lung disorder characterized, at an early age, by bacterial deposition in the airways, the production of thick, infected mucus, combined with an hypersecretory state of serous cells $^{1}$ as well as a chronic airway inflammation dominated by neutrophils. ${ }^{2} \mathrm{CF}$ is the most common autosomal recessive genetic disorder in Caucasians. It is caused by the mutation of the cystic fibrosis transmembrane regulator (CFTR) gene which spans 250 kilobases on chromosome $7 .^{3}$ Over 800 mutations of CFTR are associated with CF, but the most common is the deletion of phenylalanine at position 508 of the 1480-residue CFTR protein. CFTR acts as a chloride channel on the apical surface of epithelial cells, and responds to increases in intracellular levels of cyclic AMP $^{4}$ The biological perturbations are an increase in sodium and chloride concentrations in secretions, e.g. in sweat, which is a diagnostic feature, as well as in pancreatic secretions leading to pancreatic insufficiency. In the airways, there is an increase in mucus viscosity, thus impairing mucociliary clearance. ${ }^{5}$

\section{Chronic bronchial infections in CF}

CF is thus characterized by lung colonization with different types of bacteria, ultimately ending in Pseudomonas aeruginosa colonization resulting in tissue destruction by emigrating neutrophils. In addition, in situ neutrophil decomposition is the major source of the DNA that renders the sputum viscous and leads to bronchial obstruction. In the late stage, the host defence mechanisms directed at clearing the mucosa containing infecting microorganisms are greatly impaired, and consequently, bacterial pathogens are rarely eradicated from the airways even with aggressive antimicrobial treatment, whether intravenous or delivered directly to the respiratory tract by aerosol. ${ }^{6}$ Disease progression is punctuated by acute episodes of infection exacerbating respiratory tract disease, that ultimately lead to severe bronchial damage, respiratory insufficiency, and death. ${ }^{7}$ Pulmonary infections are the main cause of morbidity and mortality.

Most clinical studies designed to unravel the mechanisms causing CF patients to be highly susceptible to infections have focused on proteases, and on 
serum-mediated bacteria opsonizing dysfunction. The current explanation for the persistence of $P$. aeruginosa in the respiratory tract is the emergence of mucoid strains specific of $\mathrm{CF}$, which are resistant to phagocytosis. ${ }^{8}$ However, more recent data suggest that CFTR itself may be a major receptor for binding and internalization of $P$. aeruginos $a$ and that CFTRmediated ingestion of $P$. aeruginos $a$ is critical for early and effective clearance from the lung. ${ }^{9}$

\section{Inflammation in CF: a key role for neutrophils}

The polymorphonuclear neutrophils are also considered to be responsible for the early onset and promotion of the inflammatory process in CF. The vicious cycle of mucosal infection and lung inflammation begins within the first year of a CF patient's life. The typical pathophysiologic feature of $\mathrm{CF}$ is significant ongoing infection and airway inflammation with clinically mild lung disease. ${ }^{10}$ Several studies investigating the complex relationships between infection and inflammation in CF support the concept that the host inflammatory response is not necessarily proportional to the burden of pathogens in the respiratory tract, although these pathogens may provide the primary stimulus for such responses. ${ }^{11}$ The mechanisms leading to neutrophil-dominated inflammation in CF patients as well as the relationships with CFTR mutations remain largely unknown, and still less is known about the functional characteristics of neutrophils in CF. However, it becomes increasingly apparent that the clinical evolution of $\mathrm{CF}$ patients is more closely related to the state of airway inflammation. The airway inflammation typical of CF thus relies on the paradox of an exacerbation of neutrophil-mediated tissue damage and concomitant persistence of inflammation.

Neutrophils mediate host defence and tissue damage by two pathways: firstly, the NADPH oxidase system can produce toxic oxygen metabolites such as superoxide anion and hydrogen peroxide $\left(\mathrm{H}_{2} \mathrm{O}_{2}\right)$, while myeloperoxidase, an enzyme located in azurophil granules, catalyses the formation of chlorinated oxidants from $\mathrm{H}_{2} \mathrm{O}_{2}$ and chloride, thus giving rise to hypochlorous acid ( $\mathrm{HOCl}$ ) and chloramines, the socalled long-lived oxidants, ${ }^{12}$ secondly, non-oxygendependent mechanisms, which involve preformed proteins (proteinases and antibiotic proteins) mainly stored in azurophil granules. ${ }^{13}$ Although the two mechanisms can function independently, synergy is needed for a fully bactericidal and destructive response.

High concentrations of neutrophil-derived mediators are found in airways, in particular inflammatory cytokines such as IL-8 ${ }^{14}$ and TNF- $\alpha$; metalloproteases such as gelatinase; serine proteases including elastase, cathepsin $G^{15,16}$ and as we recently reported, protei- nase $3,{ }^{17}$ with a clear imbalance between proteinases and antiproteinases; ${ }^{18}$ and the so-called antibiotic peptides or defensins. It has also been shown that defensin antibiotic activity might be decreased in CF lung because of the modification in ionic concentrations of the bronchial secretions. ${ }^{19}$ Most interestingly, we have shown that chlorinated oxidants were present at very high levels in bronchial secretions from CF patients, thus suggesting that they might play a modulatory role in $\mathrm{CF}$ airway inflammation in $\mathrm{CF}^{20}$

\section{Underlying mechanisms of airway inflammation: hypothesis of a genetic defect in CF neutrophils}

Several groups are beginning to characterize the role of mutant CFTR in the inflammatory process. Attention has recently been focused on a possible disruption in the autocrine control of cytokine secretion by epithelial cells characterized by a decrease in inhibitory cytokines such as IL-10 and a dramatic increase in proinflammatory cytokines such as IL-6, TNF- $\alpha$ and the strong neutrophil chemotactic cytokine IL-8. ${ }^{21}$ Activation of NFkB and IL-8 transcription have been reported in epithelial cells with CFTR mutations following exposure to Pseudomonas ligands. ${ }^{22}$ These disturbances in cytokine regulation which can be observed in the absence of detectable infection certainly contribute to amplify and perpetuate the inflammatory process. However, it is still unknown whether cytokine dysregulation could by itself trigger the initial inflammatory process and the very early migration of the neutrophils into the airways.

Among the other phagocyte derived mediators, a disturbance in nitric oxide production could also be mentioned. Indeed, Kelley et $a l^{23}$ have recently reported that the inducible isoform of nitric oxide synthase (iNOS) is constitutively expressed in the airway epithelia of non-CF mouse and human tissues but essentially absent in the epithelium of CF airways and suggested that the absence of continuous nitric oxide production in epithelial cells of CF airways may play a role in two CF-associated characteristics: hyperabsorption of sodium and susceptibility to bacterial infections.

Another aspect of research on the CF inflammatory process is based on the investigation of neutrophil functions in CF. Investigation of CF heterozygotes could provide an alternative to studying the influence of the CFTR defect in various cellular systems. CF heterozygotes carry both a normal and a mutated allele of the CFTR but are free from the clinical problems associated with CF. However, previous studies have stressed on some physiological abnormalities in intestinal and airway epithelium CF heterozygotes. ${ }^{24-27} \mathrm{~A}$ reduced sweat production by the secretory cell in response to $\beta$-adrenergic but not 
cholinergic stimulation has also been reported. Lastly, it has also been proposed that heterozygosity of the CFTR allele has been selected in certain populations because it protects against typhoid. ${ }^{28}$

With regard to neutrophil functions, only few data on CF heterozygotes are available. Although the expression of CFTR in cell types of non-epithelial origin and in blood cells such as lymphocytes has been described, the presence of CFTR mRNA in mature neutrophils has been reported only once. ${ }^{29}$ We were unable to detect CFTR protein in neutrophil membranes using Western blot analysis but the functional analysis of neutrophils from CF heterozygotes revealed disturbed neutrophil functions. Indeed, our data showing that myeloperoxidasedependent oxygenation activities are significantly higher not only in CF homozygotes but also in heterozygote parents of CF patients provided strong evidence for a genetic component to altered neutrophil function in $\mathrm{CF}^{30}$ Interestingly, this hyperproduction of intracellular myeloperoxidase-derived oxidants could be normalized by inhibition of the $\mathrm{Na}^{+} / \mathrm{H}^{+}$exchange system using amiloride or EIPA, which are pharmacological blockers, as well as in a chloline buffer which prevents the exchange system from working. The $\mathrm{Na}^{+} / \mathrm{H}^{+}$exchange system participates in phagocytosis and subsequent bacterial killing by compensating for the $\mathrm{H}^{+}$load generated by the respiratory burst and thus regulating intracellular $\mathrm{pH}$, as well as by the volume increase associated with neutrophil migration. ${ }^{31,32}$ A disturbance in this latter function might be of relevance in the mechanisms leading to excessive neutrophil influx into the airways. In addition, a recent study has pointed out a decrease in the shedding of L-selectin in stimulated CF neutrophils which was not observed in either stable or acutely infected non-CF bronchiectasis patients, thus suggesting disturbed control of the migration process in CF neutrophils. ${ }^{33}$

Taken together, these data led us to suggest that CF neutrophils show a modification of intracellular $\mathrm{pH}$ regulation which may play a role in the increased intracellular myeloperoxidase enzymatic activity. An alternative hypothesis might be a decrease in the concentration of intracellular antioxidants such as glutathione which, as we previously demonstrated, is a major scavenger of chloramines. ${ }^{34}$

\section{Novel functions for CFTR: relationships with neutrophil function and rationale for novel therapy}

Several working hypotheses indicate that CFTR could be a multifunctional protein involved in controlling ion channels or ion exchanges in the cell other than $\mathrm{Cl}^{-}$. Most interestingly, CFTR is a member of the 'ATPbinding cassette' (ABC) family of membrane transport proteins together with the P-glycoprotein associated with multidrug resistance (MDR) protein and the multidrug resistance-associated protein (MRP). ${ }^{35}$ It has been recently demonstrated that CFTR, like other $\mathrm{ABC}$ proteins, is directly involved in intracellular $\mathrm{pH}$ regulation since its overexpression in NIH3T3 cells decreases intracellular $\mathrm{pH} .{ }^{36}$ Defective acidification of intracellular organelles has also been shown in nasal polyp cells isolated from CF children ${ }^{37}$ but was not verified by recent studies of Golgi $\mathrm{pH}$ in cells from CFTR null mice. ${ }^{38}$ Moreover, CFTR appears also to be a glutathione transporter, a function that is shared by other ABC proteins. ${ }^{39}$

Although we do not have evidence whether a disturbance in $\mathrm{Na}^{+} / \mathrm{H}^{+}$antiport in neutrophils from CF homozygotes or heterozygotes is attributable to a defect in CFTR function, our findings showing an increase in MPO-dependent oxidant generation might also be discussed in the light of the novel functions of CFTR. In this setting, it could be speculated that the disturbance in intracellular $\mathrm{pH}$ regulation and/or the defect in intracellular glutathione concentration might be attributable to CFTR mutation in CF.

\section{Antiinflammatory approaches and clinical follow-up of the CF patient: the neutrophils as the major target}

As CF involves chronic active inflammation and recurrent infections ultimately resulting in inflammation, clinical management of CF presents a paradox combining antibiotherapy and antiinflammatory drugs.

Within the past 20 years, vigorous antibiotic therapy, clearance of mucus and nutritional repletion have been the pillars of conventional CF therapy. ${ }^{6,7}$ Prospects for effective gene therapy of the respiratory effects of CF are improving slowly and attention has been focused on complementary approaches to counteract the symptoms of CF. Several studies have identified the host inflammatory response as a potential target for therapy to delay the progression of lung function impairment in CF patients. However, the diagnosis of pulmonary exacerbation is rendered difficult in that many CF children do not present with fever and leukocytosis, and thus, the diagnosis of an acute exacerbation must be made on a subjective basis. In addition, evaluation of the airway inflammatory process is hampered by the fact that, to date, no clinical tests provide a reliable index of the in situ pulmonary inflammatory state without invasive tests. We have recently shown that neutrophil myeloperoxidase activity correlates with the inflammatory and the infectious state of very young $C F$ patients in whom functional pulmonary tests cannot be performed. ${ }^{40}$ Most interestingly, measurement of this inflammatory index has proven to be of value in evaluating the efficacy of antibiotherapy. Since less than a millilitre of blood is required for this analysis, 
evaluation of the inflammatory state could be critical to assess the efficacy of future antiinflammatory therapy.

A study of the non-steroidal antiinflammatory agent ibuprofen demonstrated its effectiveness in slowing the progression of lung disease (evaluated by pulmonary-function testing), in slowing the decline of the percentage of ideal body weight, and in decreasing the number of hospital admissions during the time of treatment. ${ }^{41}$

Antiproteinase therapy has also been proposed and aerosolization of $\alpha 1$-antitrypsin or secretory leukoproteinase inhibitor (SLPI) have proven to exert a beneficial effect on pulmonary function. ${ }^{42-44}$

A different starting point for clinical research in CF treatment led to the proposal that amiloride could improve CF clinical status. The administration of amiloride aerosols to CF patients is based on its $\mathrm{Na}^{+}$ channel blocking properties at the level of the airway epithelia. Amiloride treatment enhances water secretion from the cells, increases mucus hydration, improves mucociliary clearance and delays decline in lung function. It is tempting to speculate that the beneficial effect of amiloride might be due to its corrective effect on MPO-dependent oxidant hyperproduction. ${ }^{45}$

More recently, colchicine has been proposed as antiinflammatory therapy in CF. The rationale for this proposal relies on the initial clinical observation that chemotherapy performed on a CF patient had a clearly beneficial effect on the symptoms of $\mathrm{CF}^{46} \mathrm{The}$ current hypothesis of this effect is that cancer chemotherapy might induce overexpression of some ABC proteins such as MDR and MRP which might functionally complement CFTR. As a corollary, it can be suggested that another $\mathrm{ABC}$ protein inducer, less toxic than an antitumour drug, might complement CFTR. Colchicine, which is both an ABC protein inducer and an antiinflammatory agent with direct effects on neutrophils, has thus been proposed as a good candidate. ${ }^{47}$

\section{Conclusion}

Neutrophils play a dual role in CF, an antiinfectious role in fighting pathogens, and a proinflammatory role, in releasing its deleterious mediators. It has been repeatedly demonstrated that the clinical outcome of patients is directly related to the management of inflammation. The promise of a new approach to treatment depends on preserving airway epithelial integrity, which in turn is linked to controlling the intensity of the inflammatory response.

Nonetheless, for the clinical management of CF it is extremely important both to investigate the causes of recruitment of neutrophils, and to manage chronic airway inflammation. Better knowledge of fundamental defects in neutrophil function in CF will allow identification of potential new clinical targets and aid selective therapeutic action aimed at counteracting the lethal neutrophil-induced airway inflammation. It might possible that, instead of being simply one actor in the host defence against infectious agents, neutrophils should be considered as genetically predisposed to exacerbated inflammatory response. This exciting new area of constitutive disturbance in $\mathrm{CF}$ neutrophils is currently under study in our laboratory.

\section{References}

1. Boat TF, Welsh MJ, Beaudet AL. Cystic fibrosis. In: Scriver R, Beaudet AL, Ly WS, Valle D, eds. The Metabolic Basis of Inberited Disease. New York: McGraw-Hill, 1989: 2649-2680.

2. Cantin A. Cystic fibrosis lung inflammation: early, sustained and severe. Am J Respir Crit Care Med 1995; 151: 939-941.

3. Riordan JR, Rommens JM, Kerem B, et al. Identification of the cystic fibrosis gene: cloning and characterization of complementary DNA. Science 1989; 245: 1066-1073.

4. Welsh MJ, Smith AE. Molecular mechanisms of CFTR chloride channel dysfunction in cystic fibrosis. Cell 1993; 73: 1251-1254.

5. Stern R. The diagnosis of cystic fibrosis. New Engl J Med 1997; 336 487-491.

6. Friend PA. Pulmonary infection in cystic fibrosis. J Infect Dis $1986 ; 13$ 55-72.

7. Fiel SB. Clinical management of pulmonary disease in cystic fibrosis Lancet 1993; 341: 1070-1074.

8. Baltimore RS, Mitchell M. Immunologic investigations of mucoid strains of Pseudomonas aeruginosa: comparison of susceptibility to opsonic antibody in mucoid and non-mucoid strains. J Infect Dis 1980; 141: 238-247.

9. Pier GB, Grout M, Zaidi TS. Cystic fibrosis transmembrance regulator is an epithelial cell receptor for clearance of Pseudomonas aeruginosa from the lung. Proc Natl Acad Sci USA 1997; 4: 12088-12093.

10. Khan TZ, Wagner JS, Bost T, Martinez J, Accurso FJ, Riches DWH. Early pulmonary inflammation in infants with cystic fibrosis. Am J Respir Crit Care Med 1995; 151: 1075-1084.

11. Regelmann WE, Siefferman CM, Herron JM, Elliott GR, Clawson CC, Gray BH. Sputum peroxidase activity correlates with the severity of lung disease in cystic fibrosis. Pediatr Pulmonol 1995; 19: 1-9.

12. Klebanoff SJ. Oxygen metabolites from phagocytes. In: Gallin JI, Goldstein IM, Snyderman R, eds. Inflammation: Basic Principles and Clinical Correlates. New York: Raven Press, 1992: 541-589.

13. Lehrer RI, Ganz T. Antimicrobial polypeptides of human neutrophils. Blood 1990; 76: 2169-2181.

14. Richman-Eisenstat JB, Jorens PG, Hébert CA, Ueki I, Nadel JA. Interleukin-8: an important chemoattractant in sputum of patients with chronic inflammatory airway diseases. Am J Pbysiol 1993; 264: L413-L418.

15. Suter S, Schaad UB, Roux L, Nydegger UE, Waldvogel FA. Granulocyte neutral proteases and Pseudomonas elastase as possible causes of airway damage in patients with cystic fibrosis. J Infect Dis 1984; 149: 523-531.

16. Goldstein W, Döring G. Lysosomal enzymes from polymorphonuclear leukocytes and proteinase inhibitors in patients with cystic fibrosis. Am Rev Respir Dis 1986; 134: 49-56.

17. Witko-Sarsat V, Halbwachs-Mecarelli L, Schuster A, Nusbauh P, Ueki I, Canteloup S, Lenoir G, Descamps-Latscha B, Nadel JA. Proteinase 3, a potent secretagogue in airways, is present in cystic fibrosis sputum. Am J Resp Cell Mol Biol 1998; 20: in press.

18. Birrer P, McElvaney NG, Rudeberg A, et al. Protease-antiprotease imbalance in the lungs of children with cystic fibrosis. Am J Respir Crit Care Med 1994; 150: 207-213.

19. Goldman MJ, Anderson GM, Stolzenberg ED, Kari UP, Zasloff M, Wilson JM. Human beta-defensin- 1 is a salt sensitive antibiotic in lung that is inactivated in cystic fibrosis. Cell 1997; 88: 553-560.

20. Witko-Sarsat V, Delacourt C, Rabier D, Bardet J, Nguyen AT, DescampsLatscha B. Neutrophil-derived long-lived oxidants in cystic fibrosis sputum. Am J Respir Crit Care Med 1995; 152: 1910-1916.

21. Bonfield TL, Panuska JR, Konstan MW, et al. Inflammatory cytokines in cystic fibrosis lungs. Am J Respir Crit Care Med 1995; 152: 2111-2118

22. Prince A. Activation of NFkB and IL-8 transcription in cells with CFTR mutations. Pediatr Pulmonol 1998; Suppl 17: 103.

23. Kelley TJ, Drumm ML Inducible nitric oxide synthase expression is reduced in cystic fibrosis murine and human airway epithelial cells. $J$ Clin Invest 1998; 102: 1200-1207.

24. Hansson GC. Cystic fibrosis and chloride-secreting diarrhoea letter Nature 1988; 333: 711 
25. Davis PB, Vargo K. Pulmonary abnormalities in obligate heterozygotes for cystic fibrosis. Thorax 1987; 42: 120-125.

26. Sato K, Sato F Variable reduction in beta-adrenergic sweat secretion in cystic fibrosis heterozygotes. J Lab Clin Med 1988; 111: 511-518.

27. Prince A. The CFTR advantage-capitalizing on a quirk of fate. Nature Med 1998; 4: 663-664.

28. Gabriel SE, Brigman KN, Koller BH, Boucher RC, Stutts MJ. Cystic fibrosis heterozygote resistance to cholera toxin in the cystic fibrosis mouse model. Science 1994; 266: 107-109.

29. Yoshimura K, Nakamura H, Trapnell BC, et al. Expression of the cystic fibrosis transmembrane conductance regulator gene in cells of nonepithelial origin. Nucleic Acids Res 1991; 19: 5417-5423.

30. Witko-Sarsat V, Allen RC, Paulais M, Bessou G, Lenoir G, DescampsLatscha B. Disturbed myeloperoxidase-dependent activity of neutrophils in cystic fibrosis homozygotes and heterozygotes, and its correction by amiloride. J Immunol 1996; 157: 2728-2735.

31. Grinstein S, Furuya W, Biggar WD. Cytoplasmic pH regulation in normal and abnormal neutrophils. J Biol Chem 1986; 261: 512-514.

32. Rosengren S, Henson PM, Worthern GS. Migration-associated volume changes in neutrophils facilitates the migration process. Am J Physiol 1994; 267: C1623-C1627.

33. Russell KJ, McRedmond J, Mukherji N, et al. Neutrophil adhesion molecule surface expression and responsiveness in cystic fibrosis. $\mathrm{Am} \mathrm{J}$ Respir Crit Care Med 1998; 157: 756-761.

34. Witko-Sarsat V, Nguyen AT, Descamps-Latscha B. Immunomodulatory role of phagocyte-derived chloramines involving lymphocyte glutathione. Med Inflamm 1993; 2: 235-241.

35. Hoof T, Demmer A, Hadam MR, Riordan JR, Tümmler B. Cystic fibrosistype mutational analysis in the ATP-binding cassette transporter signature of human P-glycoprotein MDR1. J Biol Chem 1994; 269: 20575-20583.

36. Wei LY, Hoffman MM, Roepe PD. Altered pH regulation in 3T3/CFTR clones and their chemotherapeutic drug-selected derivatives. Am J Physiol 1997; 272: C1642-C1653.

37. Barasch J, Kiss B, Prince A, Saiman L, Gruenert D, Al-Awqati Q. Defective acidification of intracellular organelles in cystic fibrosis. Nature 1991; 352: $70-73$.

38. Kim JH, Grinstein S, Cotton CU. Measurement of Golgi pH in epithelial cells from normal and CFTR null mice. Pediatr Pulmonol 1998; Suppl 17: 211
39. Linsdell P, Hanrahan JW. Glutathione permeability of CFTR. Am J Physiol 1998; 275: C323-326.

40. Witko-Sarsat V, Halbwachs-Mecarelli L, Sermet-Gaudelus I, Bessou G, Lenoir G, Allen RC, Descamps-Latscha B. Priming of blood neutrophils in cystic fibrosis children: correlation between functional and phenotypic expression of opsonin receptors pre- and post-PAF priming. $J$ Infect Dis 1999; 179: 151-162.

41. Konstan MW, Byard PJ, Hoppel CL, Davis PB. Effect of high-dose ibuprofen in patients with cystic fibrosis. N Engl J Med 1995; 332 : 848-854.

42. Stockley RA. The role of proteinases in the pathogenesis of chronic bronchitis. Am J Respir Crit Care Med 1994; 150: S109-S113.

43. McElvaney NG, Hubbard R, Birrer P, et al. Aerosol alpha-1-antitrypsin treatment for cystic fibrosis. Lancet 1991; 337: 392-394.

44. McElvaney NG, Nakamura $\mathrm{H}$, Birrer $\mathrm{P}$, et al. Modulation of airway inflammation in cystic fibrosis. In vivo suppression of interleukin-8 levels on the respiratory epithelial surface by aerosolization of recombinant secretory leukoproteinase inhibitor. J Clin Invest 1992; 90 : 1296-1301.

45. Knowles MR, Church NL, Waltner WE, et al. A pilot study of aerosolized amiloride for the treatment of lung disease in cystic fibrosis. $N$ Engl J Med 1990; 322: 1189-1194.

46. Lallemand JY, Stoven V, Annereau JP, Boucher J, Blanquet S, Barthe J, Lenoir $\mathrm{G}$. Induction by antitumoral drugs of proteins that functionally complement CFTR: a novel therapy for cystic fibrosis? Lancet 1997; 350: 711-712.

47. Sermet-Gaudelus I, Stoven V, Annereau JP, Witko-Sarsat V, Reinert P, Guyot M, Descamps-Latscha B, Lallemand JY, Lenoir G. Interest of colchicine for the treatment of cystic fibrosis patients. Preliminary report. Med Inflamm 1999; 8: 13-15.

ACKNOWLEDGEMENTS. This work was supported by grants from the Association Fran aise de Lutte contre la Mucoviscidose (AFLM) and the Association pour l'Aide à la Recherche contre la Mucoviscidose et l'Assistance aux Malades.

\section{Received 17 November 1998; accepted in revised form 18 December 1998}




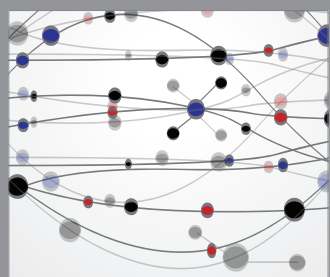

The Scientific World Journal
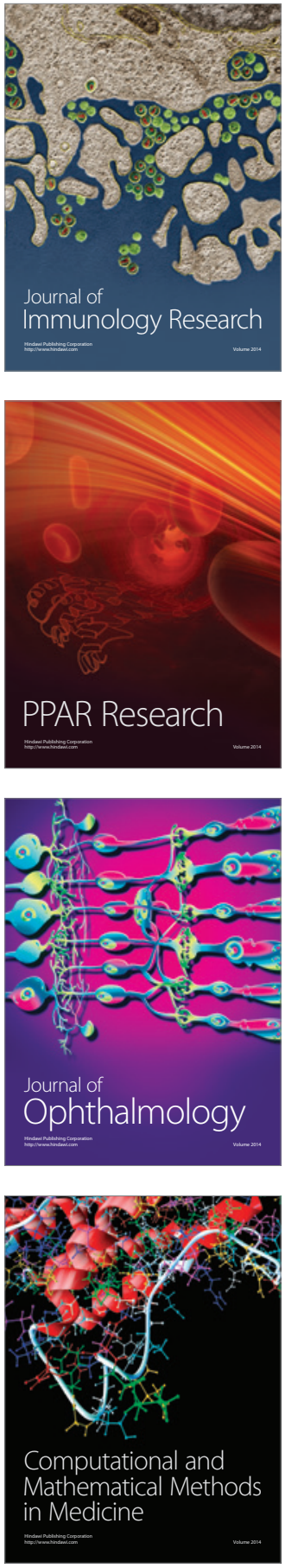

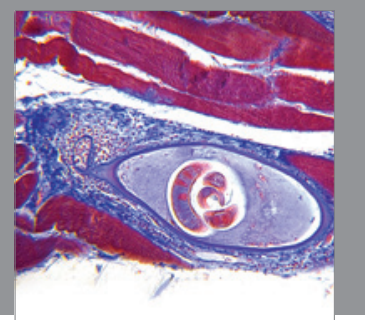

Gastroenterology

Research and Practice
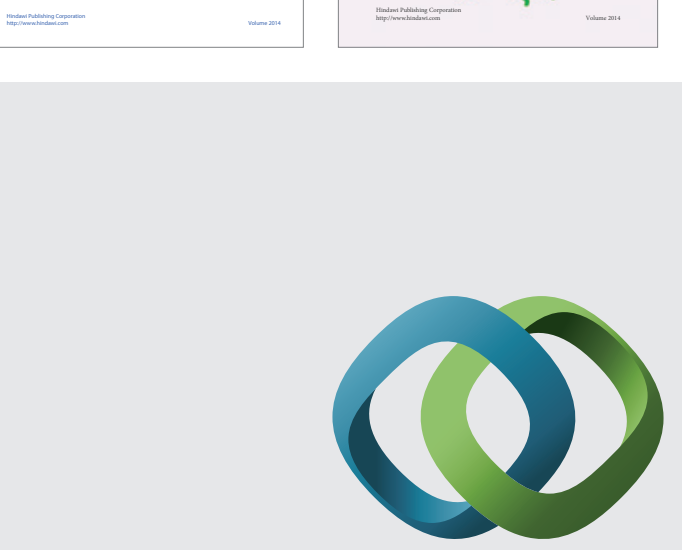

\section{Hindawi}

Submit your manuscripts at

http://www.hindawi.com
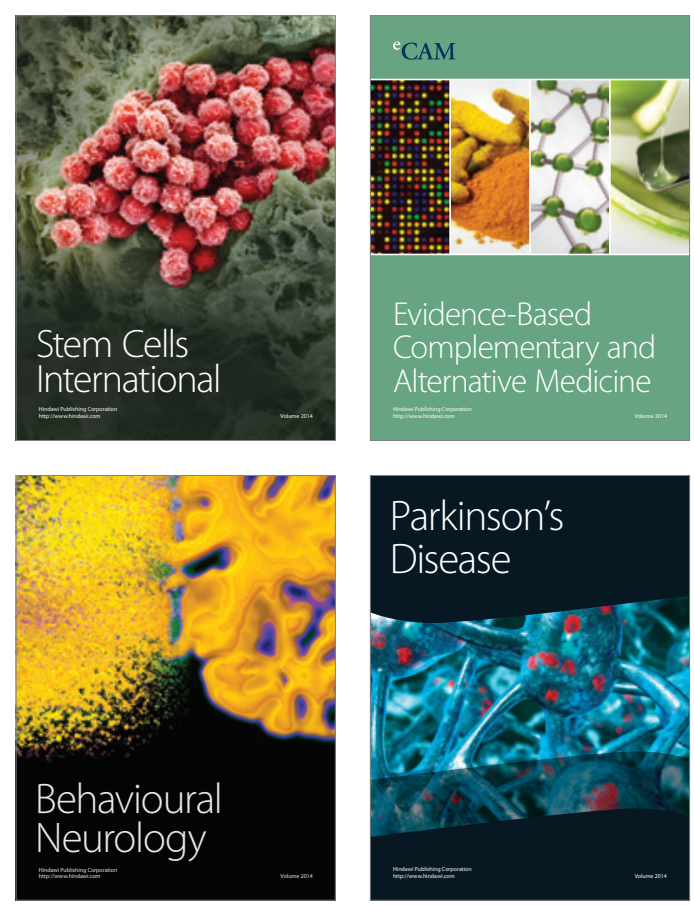

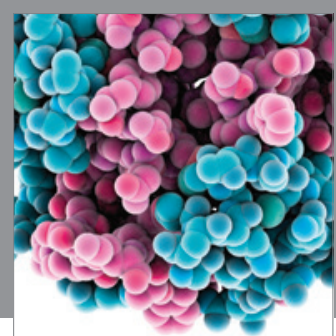

Journal of
Diabetes Research

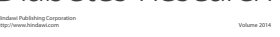

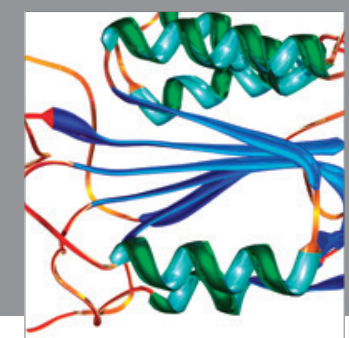

Disease Markers
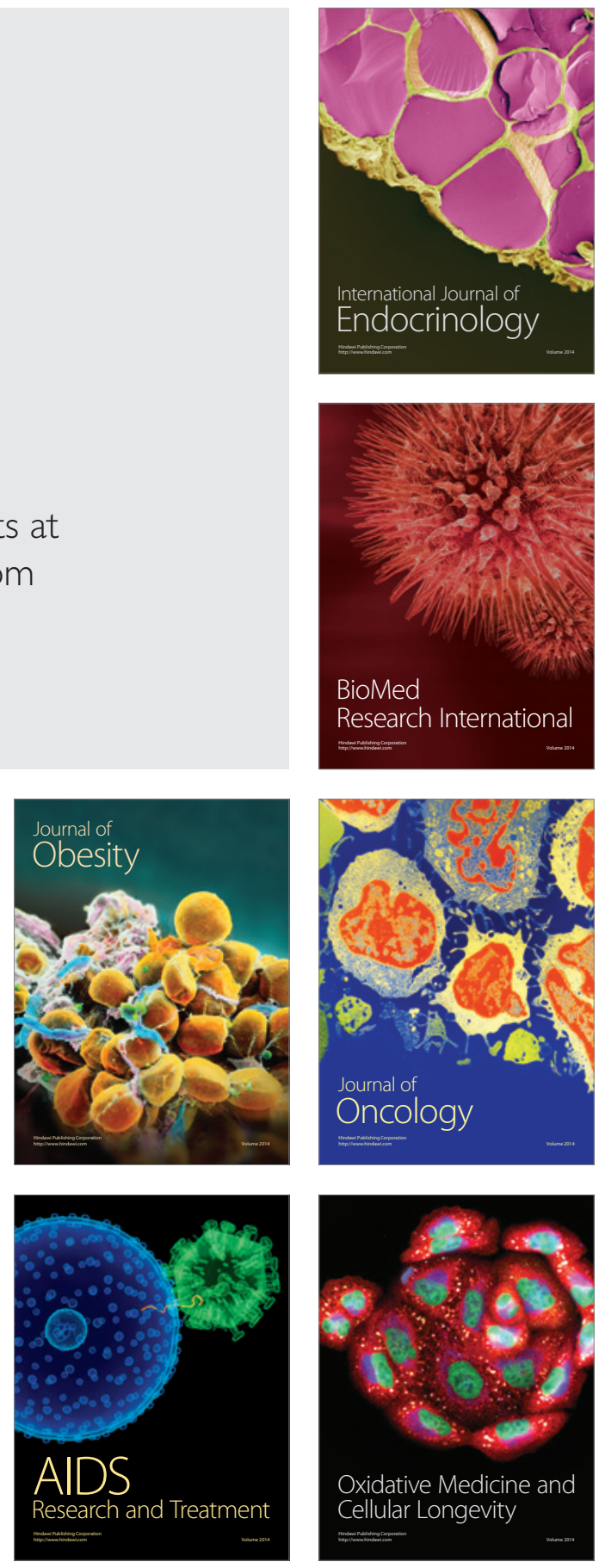